\title{
Cognitive Demand and Reminders Effect on Time-Based Prospective Memory in Amnesic Mild Cognitive Impairment (AMCI) and in Healthy Elderly
}

\author{
Olimpia Pino, Francesca Poletti, Paolo Caffarra \\ Department of Neurosciences, University of Parma, Parma, Italy \\ Email: olimpia.pino@unipr.it
}

Received April 18, 2012; revised May 25, 2012; accepted June 4, 2012

\begin{abstract}
Individuals with-Mild Cognitive Impairment (MCI) often complain of difficulty remembering to carry out intended actions. We investigated the relative efficacy of a different reminder in performing a time-based Prospective Memory (PM) task. The PM performance of 24 participants with Amnesic Mild Cognitive Impairment (AMCI) has been compared with that of 24 healthy controls. As ongoing task, samples of the Attentive Matrices Test were used. In the PM task subjects were requested to write an " $X$ " every three minutes during a 9 minutes period. Participants received the task consisting either in a low demand condition (checking number " 5 ”) or in a high demand condition (checking numbers “1”, “4”, “9”). In order to be as punctual as possible, participants were asked to simultaneously write the " $X$ " at task time expiration, using a digital clock. Time monitoring was recorded. Reminder occurring was manipulated in that participants could receive critical, accidental or completely absent reminder. As expected, high cognitive demand was negatively correlated with PM performance and time monitoring. Unexpectedly, all the participants did not benefit from the critical reminder. These findings demonstrated, from a behavioral perspective, that Working Memory (WM) and PM processes are not based on the same memory system and PM may require WM resources at high demand.
\end{abstract}

Keywords: AMCI; Prospective Memory; Time Monitoring; Memory Reminder

\section{Introduction}

Prospective Memory (PM), defined as memory for actions to be performed in the future, is one of the most fundamental aspects of everyday activities that have inspired a large numbers of researches [1,2]. In particular, PM impairments in old age and neurological conditions such as Mild Cognitive Impairment (MCI) have recently gained a growing interest, seeing that a successful functioning of PM allows an independent living and preserves autonomy in everyday life [3-7]. PM is a complex process involving at least four steps: 1) intention formation-the period during which the future activities are planned (i.e., what to do and when to do it); 2) intention retention-the period during which the intention is held in memory while other activities are occurring (i.e., ongoing task); 3) intention initiation, that is the point at which the appropriate cue triggers an effortful and controlled search of memory for the intention; 4) intention execution-when the retrieval context actually occurs and the action of the intended action is performed [8]. In time-based prospective tasks the intended action has to be performed at a specific point in time or when an exact period of time has elapsed [9]. It is therefore un- surprising that many laboratory studies focused their attention on PM time-based tasks that seem crucial for independent living and more adapted to underlie age-related PM impairment than event-based tasks [10,11]. According to Craik's theory [12], time-based execution is more dependent on self-initiated mental activities, such as active monitoring in that individuals cannot use external cues, as in event-based tasks [13]. Thus, it was demonstrated that young and old people progressively increase their time-monitoring during the critical period (the last few minutes of the interval) and this behavior seems to determine a successful performance. The same time-monitoring pattern was showed by young and healthy old, even if old participants monitoring was less frequent than young one [13,14]. Moreover, a similar pattern of time-monitoring is displayed by people's suffering from Alzheimer's disease (AD), although their clock checking was less consistent than that for control subjects. Time monitoring could be influenced by the Intention Superiority Effect (ISE) [15]. Indeed, intentions seem to be represented in a higher state of subthreshold activation in memory than other kinds of information $[16,17]$. Also, ISE could increase the familiarity of to-be- 
enacted materials during the retention interval and when the action should be executed [18]. Freeman and Ellis [19] demonstrated that ISE is noticed in young adults and healthy old people but not in persons suffering from AD and persons with a diagnosis of Amnesic Mild Cognitive Impairment (AMCI), label commonly referred to persons who exhibit a memory impairment even though do not fulfill criteria for dementia. Further, healthy old, AMCI and $\mathrm{AD}$, following the action completion, show a failure in deactivating action representations. Probably this represents a general characteristic of old age and not a specific deficit of MCI or AD. In a typical PM task, retention of the action or retrieval context may fail. This is the common experience of knowing that you have to do something but not remembering what it is. Conversely, retrieval of the delayed intention may occur at inappropriate time. According to Einstein and McDaniel [2-8], these situations refer to the retrospective and prospective components of a PM task, respectively. Although both components involve conscious episodic recollection, only the retrospective component (remembering that and what to do) is characteristically an episodic memory function mediated by temporal-limbic systems [20]. The central executive is assumed to allocate resources for managing the maintenance of information while temporarily performing other activities. Consequently, one idea is that the demands of ongoing activities can usurp resources required by the prospective task, resulting in interference. This hypothesis can be addressed by evaluating whether cue detection during an ongoing activity requires processing resources (as in PAM model), or can be done (almost) automatically (as in multiprocess theory). From a neuropsychological perspective, both PM and WM are considered executive processes, being localized in prefrontal regions such as the bilateral rostrolateral prefrontal areas, the frontopolar cortex, and the dorsolateral prefrontal cortex (DLPFC). From the gateway theoory the role of the rostrolateral prefrontal regions may be related to both maintenance of intentions and attentional shift from internal thoughts to external activating stimuli. In addition, the DLPFC is thought to be connected to the active maintenance of these actions and/ or to inhibitory processes.

Laboratory-based findings indicate that, for both young and old participants, more the ongoing task involves working memory processes, fewer resources would be available to perform PM task [14-21]. Marsh and Hicks [22] showed that PM performance is impaired only when performing an ongoing task requires Central Executive System processes (CES) [23]. Indeed, CES seems to control the executive processes, like monitoring, planning and inhibition, necessary to perform a PM task. In particular, these processes are essential for enacting timebased PM activities, where CES should inhibit the ongo- ing task allowing time-monitoring. A recent study [24] aimed to assess whether WM and PM share re- sources or are, alternatively, two distinct mechanism have used transcranial magnetic stimulation (TMS) showing that WM and PM processes are partially dissociated and PM appear not compete for the same resources, except at high level of WM demand (TMS produced interference effects on the DLPFC only with higher levels of the WM ongoing task). This finding supports a multi-process view of prospective memory. At least, the use of external reminder is another variable that could improve intention fulfillment especially in old subject. Actually, reminders benefit prospective performance only when they are distinctive, clear and strongly associated to intention [2], not indiscriminately and accidentally presented [25,26] and when the ongoing task does not require heavy attentive resources [27]. Further, Guynn, Einstein and McDaniel [28] demonstrated that a reminder is effective only if it refers to target event and action to be performed [29]. Cook, Marsh and Hicks [30] showed that reminder improved prospective execution because it increases time monitoring that was strongly correlated to PM success.

The present study is aimed at providing evidence of the relative vulnerability of PM to the cognitive impairment in MCI [31] or, more specifically, Amnestic MCI AMCI-single or multiple domains). The importance of $\mathrm{AMCI}$ is that progression to $\mathrm{AD}$, or at least to non-specific dementia, has been reported to occur at a rate of $12 \%$ - $15 \%$ per year as distinct from $1 \%-2 \%$ in healthy adults [6]. We hypothesized that AMCI participants will be able to perform as controls a time-based PM task using a reminder that appear immediately preceding the target time. A great amount of research revealed that PM performance is strongly influenced by prefrontal cortex processes [32-35]. Consistent with the heterogeneity of cognitive abilities implied in the correct fulfillment of delayed intentions, it is generally agreed that a plurality of neural networks sustain processes that are critical at the various stages of a PM task. However, which subregions of the frontal cortical mantle are most involved in specific subcomponents of a PM task (e.g., maintenance of intention, etc.) is currently a matter of intense experimental study and theoretical discussion. Moreover, it has also been frequently suggested that other cortical area (e.g., the mesio-temporal and parietal lobe [36] and the subcortical structures (e.g., the thalamus) [37] also are implied in spontaneous retrieval for PM behaviors as well as different areas within these systems. Other functional imaging studies and lesions investigations [38,39] have shown consistent activation in rostral PFC (in Broadman area-BA-10) suggesting a possible role for polar prefrontal structures supporting in time estimation and in retrieving an intention to act. Questions related to PM functioning are interesting not only at the theoretical 
point of the view. Indeed, understanding the functional and anatomical underpinning of PM could congruently inform both neuropsychological assessment and rehabilitative intervention in affected individuals [40]. Indeed, the prefrontal cortex seems to support executive functioning required for planning and carrying intention into action, inhibiting the ongoing activity when a PM cue is encountered or shifting the attention between external context and internal thoughts such as maintaining the intention in a heightened state of activation [41-43]. Thus, a decline of PM performance would be associated to impairment in executive functioning [44-46]. On the other hand, the memory system of the medial temporal lobes is assumed to be essential for retrospective component [47]. In order to examine this issue, in the present research a neuropsychological battery was applied to AMCI subjects and normal controls to obtain several measures of cognitive abilities (such as processing speed, inhibitory control, planning or verbal and visual-spatial memory). We explored the relationship between prospective functioning and other cognitive processes correlating neuronpsychological tests with PM performance.

In contrast to the extensive literature on normal aging and Alzheimer's disease (AD) [9,10,48-52], only few investigations of PM concerned MCI subjects [31,53-56]. It was showed that AMCI participants performed significantly poorer than healthy controls on all PM tasks suggesting that time-based PM tasks may be sensitive to the earliest cognitive changes associated with AMCI, possibly reflecting decreased self initiation, attention switching and/or inhibition on memory tasks due to early involvement of the frontal system whereas. Karantzoulis et al. [53] study suggested that PM impairment in AMCI is associated with deficient cue detection processes. These difficulties are likely due to a combination of problematic retrospective episodic memory (e.g., reduced encoding and/or consolidation of cue-intention pairings) and executive functioning (e.g., decreased self-initiation, attention switching, and/or inhibition on memory tasks). Costa et al. [54] results confirmed that PM is severely impaired in individuals with AMCI and that failure in both prospective and retrospective components underlies the PM impairment. Finally, the finding that a deficit in executive control does not fully account for the PM deficit suggests the involvement of automatic-reflexive processes. Seeing that MCI people show deficits either in tasks requiring heavy attentive and executive resources $[6,53,54,56]$, and in maintaining active intentions in memory [19], we anticipated that, when the cognitive demand of ongoing task increases, amnesic MCI performance will be impaired in a significant manner respect to that of healthy controls. The evidence regarding the need for cognitive resources is mixed. This is probably due to the fact that experimental procedure vary widely regard- ing the nature of the ongoing tasks, the way that cognitive load is manipulated, and the kind of prospective memory task. For example, some studies, in agree with the monitoring view, showed that dividing attention leads to worse prospective remembering [57-59]. PM also suffers if difficulty of an ongoing task is increased [25]. Thus, we manipulated the ongoing task cognitive demand in two conditions: 1) low demand condition, in which the ongoing task required the use of spare attentive resources and; 2) high demand condition, in which the ongoing task involved more attentive resources. According to findings of Guynn et al. [28], a reminder that refers to the target action and the execution time was used. Subjects could participate in one of three different reminder occurrences: critical (the reminder appeared a few of seconds before the target time), accidental (it was randomly presented during the ongoing task) and absent (no reminder). Seeing that time-based PM performances are improved by contingent reminder [26-28], the main aim of the present research was to determine whether in AMCI patients the WM ongoing task load produce effect on PM task depending on the amount of the WM load: being stronger at higher demands of WM, while PM task at lower levels of WM demand were not affected. The centrality of DLPFC has been supported by several studies but the relationships between WM and PN has not produced conclusive data on the interaction between WM-ongoing task and PM task. Furthermore, both accuracy with PM task and reaction times were essential because the ongoing and prospective tasks are in competition, as participants were asked to provide a dual-response elucidating the interaction between ongoing activity and processing of intentions.

The second hypothesis concerned the frequency and the pattern of time monitoring. According to Harris and Wilkins' perspective [12], all the participants should increase their clock checks immediately preceding target time. Monitoring, as conceptualized in the PM model $[60,61]$, cannot be completely applied to the time-based tasks where internal but not external PM cues associated with planned intention. Specifically, strategic monitoring is conceptualized to be composed of two independent mechanisms: retrieval mode and target checking. Retrieval mode is a neurocognitive task set to treat either internal or external stimuli as cues to retrieve intentions; this is a mechanism based on maintaining the representation of intention active in memory. In contrast, target checking is an intermittent mechanism that consists in monitoring the passage of the time mediated by clock checking. In time-based tasks the PM cue (i.e., the appropriate time) is intrinsically predictable and individuals are engaged in time monitoring only periodically, as the occurrence of the PM cue approaches. The strategic monitoring mechanisms supporting PM were also objects 
of interest for neuroimaging studies. These studies converged in indicating the anterior part of prefrontal cortex (aPFC, BA-10) as the core brain region in maintaining active the intention during ongoing activity with a dissociation within aPFC showing the activation of a more inferior area in the time-based task. A recent investigation [62] provide the first evidence for the electrophysiological correlates of strategic monitoring. The frontal and prefrontal distribution of ERP modulation is in line with the notion that the retrieval mode is mediated by the activity in the frontal cortex and also extend the results of neuroimaging studies suggesting that prefrontal cortex is involved in maintaining delayed intentions. Furthermore, it is possible that this frontal activity reflected the engagement of executive resources required for managing and holding in mind more tasks/goals simultaneously. Nevertheless, it is unlikely to imagine that this is the only process related to the ERP modulation. Particularly with high demanding ongoing tasks, where the cost of managing more tasks concurrently is increased, we cannot exclude the influence of another process specifically involved in time-based PM, namely the internal time estimation. We expected that time monitoring frequency would be reduced in high demand condition because of a non complete availability of executive and attentive resources. In particular, seeing that AMCI are so negatively influenced in dual-task situations [55,58,59], AMCI participants were also expected to show a less frequent clock checking pattern (reflecting strategic monitoring) and a decline of performance (i.e., slowing of reaction times and decrease in accuracy) when an high load ongoing task is presented.

\section{Method}

\subsection{Subjects}

Participants included 24 individuals with AMCI and 24 age- and education-matched healthy controls. The AMCI participants were recruited from the outpatient memory clinic (Diagnosis and Care of Cognitive Disorders Unit, AUSL, Parma, Italy); they were aged between 58 and 82 years $(\mathrm{M}=70.54$; $\mathrm{SD}= \pm 7.13)$. The Mini-Mental State Examination (MMSE) and a battery of cognitive functions measures were used to select patients with a diagnosis of amnesic MCI or MCI with another impaired cognitive function more than memory [63]. Adults with self reported persisted memory problems and MMSE scores between 20 and 26 were classified as cognitive impaired. Historical and clinical features were also used to select patients that have been examined in the last sis month, without vascular damages or significant anxiety or depression state, evaluated with The Hospital Anxiety and Depression Scale (HAD, a score of 8 or more) [64].
Additionally, participants had to be living independently in the community. The battery was administered by psychologist and neuropsychiatrist trained and certified for the instruments administration. The participants had to demonstrate evidence of Peterson's [65] criteria for subjective memory complaint, objective memory impairment, normal activities of daily living, and normal general cognitive function. Exclusion criteria were: history of head injury with loss of consciousness for more than 30 min, vascular damages, past or present learning disability, medical disease, major neurological or psychiatric disorders, significant anxiety or depression state, and nonnative Italian speaker. All participants (9 men and 15 women) were AMCI. Twenty-four healthy elderly individuals, matched for age, gender, and years of education, were recruited from general practitioner's offices. All controls subjects performed within the normal range for their age on all measure in the diagnostic test battery. The AMCI adults ( $72.5 \%$ female) were individually matched with controls $(\mathrm{M}=68.38$; $\mathrm{SD}= \pm 7.86)$, which not receive any payment for participating, on gender, age and years of education. All the subjects of the control group performed within the normal range for their age on all measure in the diagnostic test battery. Written informed consent was obtained from all participants. The AMCI group had a significantly lower score on the MMSE $(p<0.001)$ as well as on various measures of retrospective memory: PM47, Dual-Task, Semantic Fluency, Verbal Fluency, Tower of London, Stroop test (time and errors), RAVLT (immediate and delayed), ROCF (immediate and delayed) [66].

\subsection{Design}

A 2 (Groups) $\times 3$ (Reminder occurrence) $\times 2$ (Cognitive demand of ongoing task) mixed factorial design with the last factor within subjects was used. The reminder occurrence (critical, accidental or none) varied between participants and the cognitive demand of ongoing task (high or low) varied within participants. Every participant was randomly assigned to each condition.

\subsection{Material and Procedure}

Subjects participated individually in sessions lasting approximately 90 minutes after giving informed consent and providing social-demographic information. Every participants underwent a neuropsychological battery that included: Raven's progressive matrices (PM 47) [67] to evaluate visual-spatial and logic abilities; Mini-Mental State Examination [63] to estimate cognitive impairment; Digit Span forward [63] and back (WAIS) [66] as working memory index; Dual-task [69] to study executive functions and the ability to perform simultaneously two different tasks; Stroop Test [70] to assess attentive capa- 
bilities and inhibitory functioning; Tower of London $[71,72]$ to evaluate mental planning, problem solving and procedural memory; phonemic fluency [68] and semantic fluency $[72,73]$ to assess capabilities to enter vocabulary by phonemic and semantic categories. At last, we used Rey Auditory Verbal Learning Test [73] to examine short and long-term verbal memory and Rey-Osterrieth complex figure [74] used as index of praxis abilities and memory for visual-spatial material. Neuropsy-chological battery scores of all participants are showed in Table 1.

To index PM a classical laboratory measure was used that was based on Einstein and McDaniel [75] paradigm. As on-going task we used some copies of Attentive Matrices Test [76]. Participants were tested individually under all testing conditions (see Figure 1). They were told that we were interested in determining their ability to complete a series of matrices and that a number of matrices copies would individually be presented for a brief period of time. To control for differences in information processing-speed the number of matrices copies was variable for the subjective speed to check the numbers but sufficient to employ the participants throughout nine minutes.

Following the practice trials, participants were given
PM task instructions. With the aim of creating a task that placed a differential degree on strategic attentive resources, two variables were manipulated: cognitive demand of the ongoing task, and reminder occurrence. Attentional cognitive demand was manipulated by varying the number of action needed to perform in order to determine the appropriate response at the ongoing task. Cognitive load conditions were counterbalanced. Participants were told to keep the instructions in mind and were asked to repeat back the instructions to ensure their learning. Subjects were told that we were also interested in studying their ability to remember to do something in the future. They were told that they should check number " 5 " (in low demand condition) and numbers " 1 ", " 4 ", and "9" (in high demand condition) during the all experimental session (each one is protracted for nine miutes). To minimize the demands of the task, the intended action was held constant. Specifically, participants were asked to simultaneously mark an $\mathrm{X}$ in the back side of the latest paper of the Attentive Matrices Test, every three minutes (PM task), verifying the time elapsing on a digital clock (digital clock checks were recording by the examiner). The digital clock indicated minutes and se-

Table 1. Scores obtained at neuropsychological battery for AMCI participants and controls.

\begin{tabular}{|c|c|c|c|c|c|c|c|c|c|c|}
\hline & $\mathrm{N}$ & Min & Max & Average & $\mathrm{SD}$ & $\mathrm{N}$ & Min & Max & Average & $\mathrm{SD}$ \\
\hline Age & 24 & 58 & 83 & $\begin{array}{c}70 \text { years; } \\
6 \text { month }\end{array}$ & $\begin{array}{l}7 \text { years; } \\
1 \text { month }\end{array}$ & 24 & 57 & 86 & $\begin{array}{l}68 \text { years; } \\
5 \text { month }\end{array}$ & 7.86 \\
\hline PM47 & 24 & 16 & 33 & 24.58 & 4.898 & 24 & 17 & 34 & 28.71 & 3.8 \\
\hline MMSE & 24 & 20 & 30 & 26.04 & 2.368 & 24 & 25 & 30 & 28.12 & 1.65 \\
\hline Digit Span (forward) & 24 & 4 & 7 & 5.17 & 0.816 & 24 & 4 & 6 & 4.95 & 0.80 \\
\hline Digit Span (back) & 24 & 2 & 4 & 3.38 & 0.770 & 24 & 2 & 5 & 3.62 & 0.77 \\
\hline Dual-task & 24 & 56 & 100 & 83.62 & 14.004 & 24 & 67 & 120.5 & 92.82 & 13.37 \\
\hline Semantic Fluency & 24 & 7 & 42 & 28.08 & 10.337 & 24 & 13 & 50 & 39.45 & 8.63 \\
\hline Verbal Fluency & 24 & 11 & 43 & 23.71 & 9.796 & 24 & 17 & 55 & 30.29 & 9.23 \\
\hline Tower of London & 24 & 16 & 33 & 26.83 & 4.824 & 23 & 24 & 33 & 28.9 & 2.78 \\
\hline Stroop (interference time) & 24 & 7 & 59 & 33.10 & 11.687 & 24 & 14 & 74.5 & 29.39 & 13.06 \\
\hline Stroop (interference errors) & 24 & -1 & 10 & 1.88 & 3.080 & 24 & -0.5 & 3 & 0.64 & 1.09 \\
\hline RAVLT (immediate recall) & 24 & 12 & 37 & 23.67 & 6.545 & 24 & 27 & 59 & 41.66 & 8.77 \\
\hline RAVLT (delayed recall) & 24 & 0 & 8 & 2.46 & 2.105 & 24 & 3 & 14 & 8.5 & 2.6 \\
\hline ROCF (copy) & 22 & 14 & 33 & 26.75 & 4.61 & 24 & 21 & 35 & 29.37 & 3 \\
\hline ROCF (delayed copy) & 23 & 0 & 31 & 9.16 & 7.405 & 24 & 5 & 20 & 12.40 & 3.68 \\
\hline
\end{tabular}




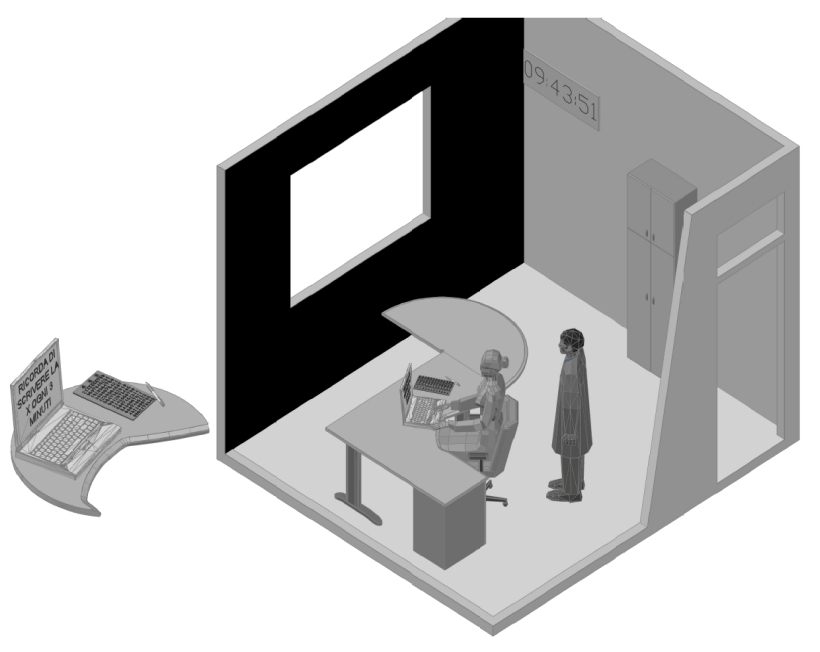

Figure 1. Representation of the experimental setting.

conds and it was situated beside the participants to make easier their time checking. The clock's digital display was large $5 \mathrm{~cm} \times 2 \mathrm{~cm}$ and the exact distance of the clock was adapted until participants reported that they could read it. The position of the clock required participants to turn their heads to monitor the clock (about $90^{\circ}$ ) and this allowed experimenter to record the number of times the participants monitored the clock. It was specified that the clock did not ring at the target times but the subjects must monitor time elapsing to their own. In our study, as the naturalistic task and in order to minimize the likelyhood of floor effects, the number of prospective responses was increased (at third, sixth, ninth minute expiration). After the instructions, participants were given the opportunity to ask questions about the task. When they had no further questions, they were told that they are receiving a reminder during the ongoing task, that consisted in a PowerPoint slide, presented by a portable PC, suggesting the PM task "Remember to write the $\mathrm{X}$ every three minutes” (typeface: capital Arial, dimension: 80). Participants were not told when the PM cue would appear. Reminders' manipulation consisted in their temporal occurrence: it could be critical, accidental or completely absent. In the critical occurrence the slide appeared 40 seconds before time expiration (at 2'20" min, 5'20" and 8'20" min, respectively). In the accidental occurrence the reminder appeared randomly (during the high load condition at 1'17" min, 4'56" min, and 7'09" min while during the low load condition at 48" sec, 4'33" min and 7'40" min, respectively). The slide was accompanied by a sound to attract attention on the reminder. At the end of the instructions, the clock was started, beginning with a display of 0 minutes and 0 seconds. Following the PM task it was verified that $100 \%$ of individuals remembered the instruction. At the end of the session, participants were debriefed.

\section{Results}

\subsection{PM Performance}

SPSS Statistical Software (15.0 Version) was used for all statistical analyses. The considered dependent variables were: accuracy (frequency of PM correct execution) and reaction time memory RTs (i.e., the sum of the time elapsed to write the " $X$ " on the sheet of paper at the time targets, maximum $180 \mathrm{sec}$ ) of PM task and pattern of time-monitoring. A mixed 2 (Groups) $\times 3$ (Reminder occurrence) $\times 2$ (Cognitive demand of ongoing task) analysis of variance (ANOVA) model was used to evaluate the accuracy in the PM task. The effect of Groups was significant $\left(F(1,42)=5.99, p=0.019, \eta^{2}=0.12\right)$. Mean accuracy among each condition revealed less clock-checks for AMCI participants (see Table 2). The ANOVA on the mean accuracy of the PM task showed no significant effects of Reminder occurrence $(F(2,42)$ $\left.=1.46, p=0.245, \eta^{2}=0.06\right)$, Cognitive demand $(F(1,42)$ $\left.=1.837, p=0.183, \eta^{2}=0.042\right)$, Groups $\times$ Reminder occurrence $\left(F(2,42)=0.29, p=0.748, \eta^{2}=0.01\right)$, Groups $\times$ Cognitive demand $\left(F(1,42)=0.015, p=0.903, \eta^{2}=\right.$ $0.00)$, Reminder occurrence $\times$ Cognitive demand $(F$ (2, $\left.42)=0.015, p=0.985, \eta^{2}=0.001\right)$, and Groups $\times$ Reminder occurrence $\times$ Cognitive demand $(F(2,42)=$ 0.289, $\left.p=0.715, \eta^{2}=0.014\right)$.

A mixed 2 (Groups) $\times 3$ (Reminder occurrence) $\times 2$ (Cognitive demand of ongoing task) analysis of variance (ANOVA) model was used to evaluate the reaction time in the PM execution. The ANOVA on RTS showed a significant effect of Group $(F(1,42)=8.905, p=0.005$, $\left.\eta^{2}=0.175\right)$, Reminder occurrence $(F(2,42)=3.938, p=$ $\left.0.027, \eta^{2}=0.158\right)$, and Cognitive demand $(F(1,42)=$ 6.912, $\left.p=0.012, \eta^{2}=0.141\right)$. The ANOVA showed no

Table 2. Mean accuracy (standard deviation in parenthesis) in PM execution are presented separately for different reminder occurrence (rows) and cognitive demand in ongoing load (columns).

\begin{tabular}{cccc}
\hline AMCI & $\begin{array}{c}\text { Reminder critical } \\
\text { occurrence }\end{array}$ & $\begin{array}{c}\text { High load } \\
\text { ongoing task }\end{array}$ & $\begin{array}{c}\text { Low load } \\
\text { ongoing task }\end{array}$ \\
\hline $\begin{array}{c}\text { Reminder accidental } \\
\text { occurrence }\end{array}$ & $1.50(1.39)$ & $0.88(1.36)$ \\
Controls & $\begin{array}{c}\text { Reminder critical } \\
\text { occurrence }\end{array}$ & $1.50(1.41)$ & $1.88(1.25)$ \\
& $\begin{array}{c}\text { Reminder accidental } \\
\text { occurrence }\end{array}$ & $2.13(0.99)$ & $2.13(1.25)$ \\
& Reminder absent & $2.00(1.31)$ & $2.25(0.89)$ \\
\hline
\end{tabular}


significant effects of Group $\times$ Reminder occurrence $(F(2$, 42) $\left.=0.967, p<0.389, \eta^{2}=0.044\right)$, Group $\times$ Cognitive demand $\left(F(1,42)=0.174, p=0.678, \eta^{2}=0.004\right)$, Reminder occurrence $\times$ Cognitive demand $(F(2,42)=$ $0.251, p=0.779, \eta^{2}=0.012$ ), and Group $\times$ Reminder occurrence $\times$ Cognitive demand $(F(2,42)=0.163, p=$ $0.850, \eta^{2}=0.008$ ). The post hoc comparisons (Bonferroni) indicated that latency on PM execution with the critical reminder occurrence $(\mathrm{M}=87.53, \pm 73.69)$ demonstrated significantly higher than with the accidental one $(\mathrm{M}=36.38, \pm 32.20)$. Inspection of the means indicated that participants with the high cognitive demand in the ongoing task $(\mathrm{M}=70.83, \pm 56.74)$ performing significantly worse than those with the low cognitive demand $(M=51.02, \pm 49.22)$. Moreover no significant differences between the reminder occurrence were found, both in high and low load cognitive demand of ongoing task, in controls as in MCI patients (respectively $X^{2}=$ 1.674, $p=0.433 ; X^{2}=0.256, p=0.880, X^{2}=3.28, p=$ $0.194 ; X^{2}=1.95, p=0.377$ ). Inspection of the means (see Table 3) shows that the demand effect decreased linearly (reflecting increasing costs) from the control condition to the high load ongoing task. In particular, the AMCI participants improved their accuracy on the PM task when the accidental reminder was present in both high $(\mathrm{M}=$ $53.00 \pm 41.32)$ and low cognitive demand $(M=34.38 \pm$ 29.92) conditions. When reminder was absent, AMCI participants showed a strong effect of interference $(\mathrm{M}=$ $103.00 \pm 76.66)$. It is therefore striking that both controls and AMCI subjects performed equally well on PM task when directed to use the accidental reminder.

\subsection{Associations between PM, Time Monitoring and Neuropsychological Variables}

No significant correlation was found between prospective memory and neuropsychological battery in controls. Instead, high demand condition performances in AMCI was positively correlated with delayed recall of ROCF ( $r$ $=0.589, p=0.006)$ and immediate recall of RAVLT $(r=$ $0.473, p=0.035$ ). Good performance in low load condition was also positively associated to delayed recall of $\operatorname{RAVLT}(r=0.467, p=0.038)$.

\subsection{Time Monitoring}

The mean clock checking responses are presented in Table 4 , and the pattern of time monitoring across all period is shown in Figures $\mathbf{2}$ and 3. The dependent variable was represented by the clock-checking frequencies in the minute immediately preceding the three time targets. A mixed 2 (Groups) $\times 3$ (Reminder occurrence) $\times 2$ (Cognitive demand of ongoing task) analysis of variance (ANOVA) was used. The main effect of Group $(F(1,46)$ $=13.202, p<0.001, \eta^{2}=0.223$ ), Reminder occurrence
Table 3. Mean response times (standard deviation in parenthesis) are presented separately for different reminder occurrence (rows) and cognitive demand in ongoing load (columns).

\begin{tabular}{cccc}
\hline & High load & $\begin{array}{c}\text { Low load } \\
\text { ongoing task }\end{array}$ & ongoing task \\
\hline AMCI & $\begin{array}{c}\text { Reminder critical } \\
\text { occurrence } \\
\text { Reminder accidental } \\
\text { occurrence } \\
\text { Reminder absent }\end{array}$ & $127.25(76.81)$ & $104.00(82.15)$ \\
Controls & $\begin{array}{c}\text { Reminder critical } \\
\text { occurrence }\end{array}$ & $74.03 .00(74.32)$ & $34.38(29.92)$ \\
& $\begin{array}{c}\text { Reminder accidental } \\
\text { occurrence } \\
\text { Reminder absent }\end{array}$ & $32.13(34.09)$ & $76.75(78.92)$ \\
& $34.88(37.52)$ & $25.25(23.47)$ \\
\hline
\end{tabular}

Table 4. Mean clock checking responses (standard deviation in parenthesis) are presented separately for different Reminder occurrence (rows) and cognitive demand in ongoing load (columns).

\begin{tabular}{cccc}
\hline AMCI & $\begin{array}{c}\text { Reminder critical } \\
\text { occurrence } \\
\text { ongoing task }\end{array}$ & $0.63(0.924)$ & $\begin{array}{c}\text { Low load } \\
\text { ongoing task }\end{array}$ \\
\hline $\begin{array}{c}\text { Reminder accidental } \\
\text { occurrence } \\
\text { Reminder absent }\end{array}$ & $1.29(1.488)$ \\
Controls & $\begin{array}{c}\text { Reminder critical } \\
\text { occurrence }\end{array}$ & $1.96(1.853)$ & $3.33(2.239)$ \\
& $\begin{array}{c}\text { Reminder accidental } \\
\text { occurrence } \\
\text { Reminder absent }\end{array}$ & $5.13(2.953)$ & $7.79(4.736)$ \\
\hline
\end{tabular}

$\left(F(2,92)=159.963, p<0.001, \eta^{2}=0.777\right)$, Cognitive demand $\left(F(1,46)=14.696, p<0.001, \eta^{2}=0.242\right)$ were confirmed indicating that clock checking was more frequent for the controls, in ongoing task with low load and without reminder.

The Group $\times$ Reminder interaction was significant $(F$ $\left.(2,92)=57.323, p<0.002, \eta p^{2}=0.125\right)$ revealing that the frequency of clock checks in AMCI participants is different from that of controls participants along the different reminder occurrences. All comparisons for reminder occurrences between groups were significant ( $p s$ $<0.05$ ), as within groups ( $p s<0.01)$. No interaction between Cognitive demand $\times$ Reminder occurrence $(F$ (2, $\left.92)=1.467, p<0.236, \eta p^{2}=0.031\right)$, and between Group, Cognitive demand $\times$ Reminder occurrence $(F(2,92)=$ 1.590, $\left.p<0.209, \eta p^{2}=0.033\right)$ achieved significance. Time-monitoring pattern increased in the minute preceding the target time, both in low and high cognitive demand ("J curve"), even if controls, as expected, were used to monitor time much more frequently, than AMCI 


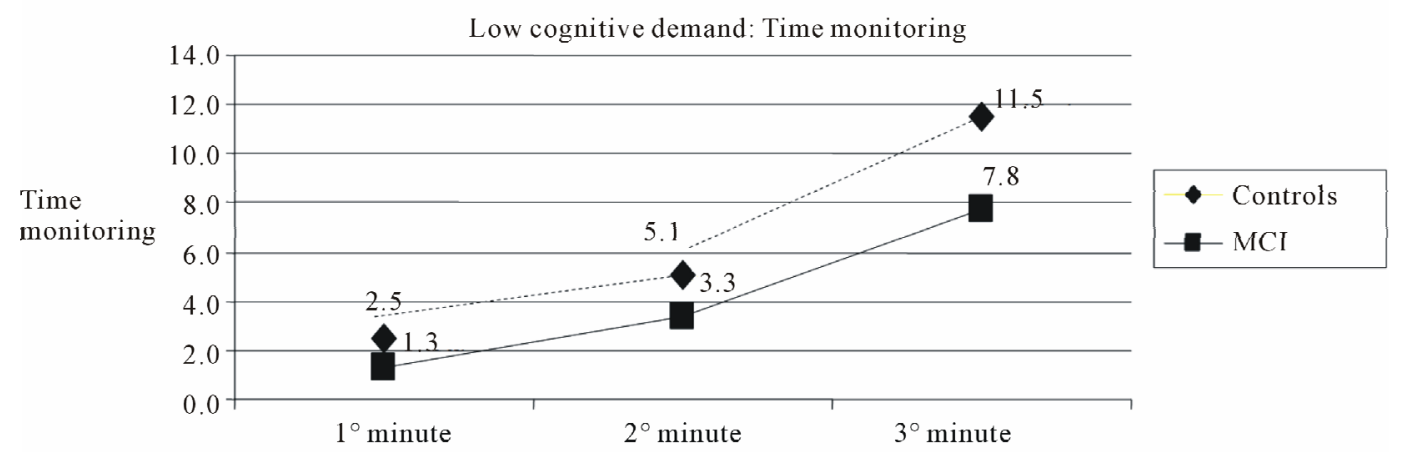

Figure 2. Time monitoring of AMCI and controls during the low cognitive demand ongoing task.

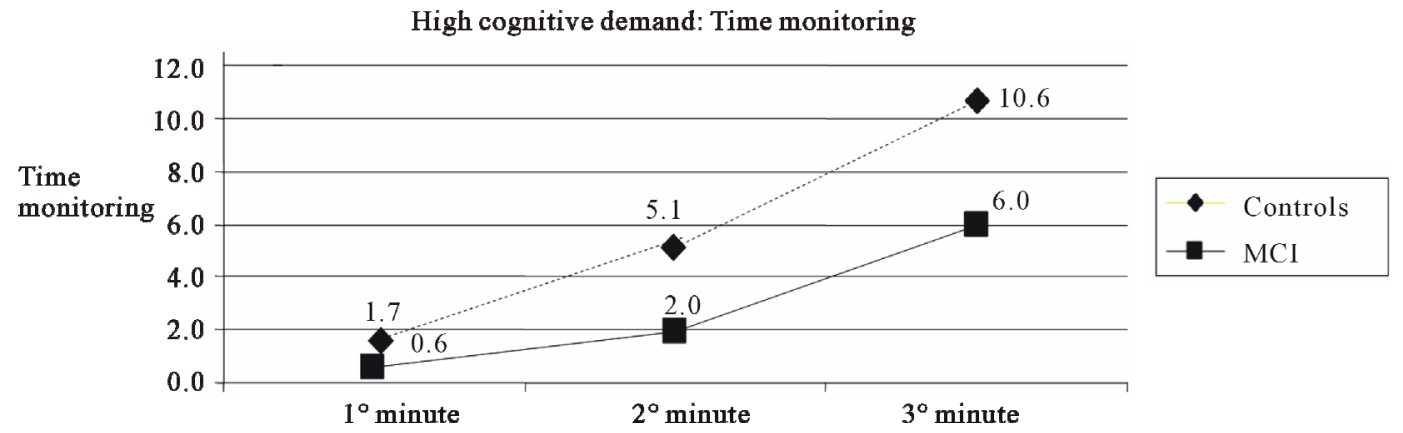

Figure 3. Time monitoring of AMCI and controls during the high cognitive demand ongoing task.

participants. In low load condition the two groups showed a similar time-monitoring pattern during the whole period, even if in the latest minute healthy participants seemed to check the clock more frequently than AMCI. In high load tasks significant differences were found during the second minute: controls time-monitoring progressively increased from the beginning to the end of every time section, while AMCI patients maintained a steady frequency of time-monitoring during the first and second minutes, improving only in the latest one.

\section{Discussion}

The present study was designed to explore how the performance in the prospective task might be influenced by the execution of the ongoing task in AMCI participants manipulating ongoing load and reminder occurrence. In particular, we are able to compare performance with a critical reminder occurrence versus an accidental occurrence and a control condition where reminder was absent. We supposed that critical reminder could improve PM for AMCI participants particularly when cognitive load of ongoing task was high because should release subjects from self-initiated time monitoring and continuous heightened activation of intention in memory. Conversely, we expected that the accidental occurrence did not influence task execution and that healthy elderly controls would outperform individuals with AMCI, given the neuropathology affecting polar prefrontal structures su- pporting in time estimation and in retrieving an intention to act. Our findings showed no support to the first hypothesis in that all the participants did not benefit from the critical reminder. These findings are likely due to a combination of impaired retrospective episodic and executive functions. As discussed previously, it is believed that executive functions, which are involved in the initial encoding, maintenance and retrieval of intentions, have an important role in sustaining this PM component. Nevertheless, it was suggested that when the experimental conditions are such that the characteristics of the ongoing task promote the processing of the PM cue, the retrieval of the intention may occur through the activity of reflexive-associative mechanisms with a relatively low demand on the attentional/executive system. In this case, the ability to store and maintain the associative link between the PM cue and the intended intention is crucial to allow the cue to trigger retrieval of the intention. Probably, in our experimental situation this is not guaranteed. The manipulation of WM load on ongoing task was effective for all participants: decreased performance, in terms RTs in PM task, was observed when WM load in the ongoing task was high, particularly for AMCI participants. An increased WM demand produced increasing RTs of the PM task, but not affect the accuracy. The second hypothesis concerned the pattern of time monitoring. We anticipated that clock checking frequency would be reduced for AMCI and in high demand condition because 
of a non complete availability of executive and attentive resources. Data confirmed this hypothesis showing that the pattern of time-monitoring resulted significantly prevailing in controls than in AMCI patients and that its pattern was not influenced by reminder occurrence or cognitive demand of ongoing task. The marginal number of correlations between neuropsychological variables and PM performance for AMCI participants confirmed that the differences obtained were not due to the encoding of prospective stimuli, but rather to the experimental manipulation of the independent variables. It appears that the cost of an intention affected the PM task by means of a slower response. These findings are consistent with previous investigations suggesting a cost of prospective intentions indicating the dorsolateral prefrontal cortex (DLPFC) and the anterior part of prefrontal cortex (aPFC, $\mathrm{BA}, 10)$ as the core brain region in maintaining active the intention during ongoing activity under high demand conditions. Our data suggest that the modulation of the WM and PM systems is not symmetrical: when faced with higher demand of the task, a specific amount of WM should be devoted to maintain the prospective stimulus. The two systems do not appear compete for the same resources, except at higher levels of WM cognitive load, supporting a multiprocess view of the prospective memory.

\section{Conclusion}

The PM functioning of patients with AMCI has also been recently investigated, possibly because of the suggestion that PM failure may be a more sensitive neuropsychological marker of intervening dementia than more traditionally investigated declarative memory deficits. The findings of our study clearly showed that an intention affect a concurrent activity under particular condition such as when demand was high, supporting the idea of a partial dissociation of WM and PM derived also from neurofunctional studies. In summary, we can conclude that PM is severely impaired in individuals with AMCI and that failure of both prospective and retrospecttive components underlies the PM impairment. Finally, the finding that a deficit in executive control does not fully account for the PM deficit suggests the involvement of automatic-reflexive processes confirming other results showing the evidence of activation in rostral prefrontal cortex (BA-10) and lateral and medial cortical areas in this region likely play differential roles, the former in keeping an intention active during performance of an ongoing task, the latter in attending stimuli in the sensory environment related to the ongoing task or PM performance. Indeed, this is an important question to answer because planning an efficient therapeutic approach requires clarification of the cognitive mechanism involved in the PM failure.

\section{REFERENCES}

[1] M. A. Brandimonte, G. O. Einstein and M. A. McDaniel, "Prospective Memory: Theory and Application," Lawrence Erlbaum Associated, Mahwah, 1996.

[2] M. A. McDaniel and G. O. Einstein, "The Importance of Cue Familiarity and Cue Distinctiveness in Prospective Memory,” Memory, Vol. 1, No. 1, 1993, pp. 23-41. doi:10.1080/09658219308258223

[3] G. J. Kinsella, E. Mullaly, E. Rand, B. Ong, C. Burton, S. Price, M. Phillips and E. Storey, "Early Intervention for Mild Cognitive Impairment: A Randomised Controlled Trial," Journal of Neurological and Neurosurgical Psychiatry, Vol. 80, No. 7, 2009, pp. 730-736. doi:10.1136/jnnp.2008.148346

[4] C. M. Will, P. G. Rendell, S. Ozgis, J. M. Pierson, B. Ong and J. D. Henry, "Cognitively Impaired Older Adults Exhibit Comparable Difficulties on Naturalistic and Laboratory Prospective Memory Tasks," Applied Cognitive Psychology, Vol. 23, No. 6, 2009, pp. 804-812. doi:10.1002/acp.1514

[5] T. Shallice and P. W. Burgess, "Deficits in Strategy Application Following Frontal Lobe Damage in Man,” Brain, Vol. 114, No. 2, 1991, pp. 727-741. doi:10.1093/brain/114.2.727

[6] R. Petersen, G. Smith, S. Waring, et al., "Mild Cognitive Impairment. Clinical Characterization and Outcome," Archives of Neurology, Vol. 56, No. 3, 1999, pp. 303-308. doi:10.1001/archneur.56.3.303

[7] J. Ellis, "Prospective Memory of the Realization of Delayed Intentions: A Conceptual Framework for Research,” In: M. Brandimonte, G. O. Einstein and M. A. McDaniel, Eds., Prospective Memory: Theory and Appli- cation, Lawrence Erlbaum Associated, Mahwah, 1996, pp. 1-22.

[8] G. O. Einstein and M. A. McDaniel, "Normal Aging and Prospective Memory,” Journal of Experimental Psychology: Learning, Memory and Cognition, Vol. 16, No. 4, 1990, pp. 717-726. doi:10.1037/0278-7393.16.4.717

[9] G. O. Einstein, M. A. McDaniel, S. L. Richardson, M. J. Guynn and A. R. Cunfer, "Aging and Prospective Memory: Examining the Influences of Self-Initiated Retrieval Processes," Journal of Experimental Psychology: Learning, Memoand Cognition, Vol. 21, No. 4, 1995, pp. 996-1007. doi:10.1037/0278-7393.21.4.996

[10] E. A. Maylor, G. Smith, S. Della Sala and R. H. Logie, "Prospective and Retrospective Memory in Normal Aging and Dementia: An Experimental Study," Memory and Cognition, Vol. 30, No. 6, 2002, pp. 871-884. doi:10.3758/BF03195773

[11] F. I. M. Craik, "A Functional Account of Age Differences in Memory,” In: F. Klix and H. Hagendorf, Eds., Human Memory and Cognitive Capabilities: Mechanisms and Performances, Elsevier, Amsterdam, 1986, pp. 409-422.

[12] J. E. Harris and A. J. Wilkins, "Remembering to Do This: A Theoretical Framework and an Illustrated Experiment," Human Learning, Vol. 1, 1982, pp. 123-126.

[13] G. O. Einstein, L. J. Holland, M. A. McDaniel and M. J. 
Guynn, "Age-Related Deficits in Prospective Memory: The Influence of Task Complexity," Psychology and Aging, Vol. 7, No. 3, 1992, pp. 471-478. doi:10.1037/0882-7974.7.3.471

[14] E. A. Maylor, "Age and Prospective Memory,” The Quarterly Journal of Experimental Psychology, Vol. 42, No. 3, 1990, pp. 471-493. doi:10.1080/14640749008401233

[15] T. Goschke and J. Kuhl, "The Representation of Intentions: Persisting Activation in Memory," Journal of Experimental Psychology: Learning, Memory and Cognition, Vol. 19, No. 5, 1993, pp. 1211-1226. doi:10.1037/0278-7393.19.5.1211

[16] J. Ellis and A. Milne, "Retrieval Cue Specificity and the Realization of Delayed Intentions," Quarterly Journal of Experimental Psychology, Vol. 49, No. 4, 1996, pp. 862- 887.

[17] R. L. Marsh and J. L. Hicks, "Event-Based Prospective Memory and Executive Control of Working Memory," Journal of Experimental Psychology: Learning, Memory and Cognition, Vol. 24, No. 2, 1998, pp. 336-349. doi:10.1037/0278-7393.24.2.336

[18] T. Goschke and J. Kuhl, "Remembering What to Do: Explicit and Implicit Memory for Intentions,” In: M. Brandimonte, G. O. Einstein and M. A. McDaniel, Eds., Prospective Memory: Theory and Applications, Erlbaum, Mahwah, 1996, pp. 53-91.

[19] J. Freeman and J. Ellis, "Aging and the Accessibility of Performed and to-Be-Performed Actions," Aging, Neuropsychology, and Cognition, Vol. 10, No. 4, 2003, pp. 298309. doi:10.1076/anec.10.4.298.28975

[20] P. W. Burgess, A. Quayle and C. D. Frith, "Brain Regions Involved in Prospective Memory as Determined by Positron Emission Tomography,” Neuropsychologia, Vol. 39, No. 6, 2001, pp. 545-555. doi:10.1016/S0028-3932(00)00149-4

[21] R. H. Logie, E. A. Maylor, S. Della Sala and G. Smith, "Working Memory in Event- and Time-Based Prospective Memory Tasks: Effects of Secondary Demand and Age,” European Journal of cognitive psychology, Vol. 16, No. 3, 2004, pp. 441-456. doi:10.1080/09541440340000114

[22] R. L. Marsh, J. L. Hicks and M. L. Bink, “Activation of Completed, Uncompleted, and Partially Completed Intentions," Journal of Experimental Psychology: Learning, Memory and Cognition, Vol. 24, No. 2, 1998, pp. 350-361. doi:10.1037/0278-7393.24.2.350

[23] A. D. Baddeley, "Exploring the Central Executive," Quaterly of Journal of Experimental Psychology, Vol. 49, No. 1, 1996, pp. 5-28.

[24] D. Basso, M. Ferrari and P. Palladino, "Prospective Memory and Working Memory: Asymmetrical Effects during Frontal Lobe TMS Stimulation,” Neuropsychologia, Vol. 48, No. 11, 2010, pp. 382-290.

[25] G. O. Einstein, M. A. McDaniel, S. L. Richardson, M. J. Guynn and A. R. Cunfer, "Aging and Prospective Memory: Examining the Influences of Self-Initiated Retrieval Processes," Journal of Experimental Psychology: Learning, Memory and Cognition, Vol. 21, No. 4, 1995, pp. 996-1007. doi:10.1037/0278-7393.21.4.996

[26] O. U. Vortac, M. B. Edwards and C. A. Manning, "Func- tion of External Cues in Prospective Memory," Memory, Vol. 3, No. 2, 1995, pp. 201-219. doi:10.1080/09658219508258966

[27] G. O. Einstein and M. A. McDaniel, "Normal Aging and Prospective Memory,” Journal of Experimental Psychology: Learning, Memory, and Cognition, Vol. 16, No. 4, 1990, pp. 717-726. doi:10.1037/0278-7393.16.4.717

[28] M. J. Guynn, M. A.McDaniel and G. O. Einstein, "Prospective Memory: when Reminder Fail," Memory and Cognition, Vol. 26, No. 2, 1998, pp. 287-298. doi:10.3758/BF03201140

[29] E. A. Maylor, "Age-related Impairment in an EventBased Prospective Memory Task," Psychological Aging, Vol. 11, No. 1, 1996, pp. 74-78. doi:10.1037/0882-7974.11.1.74

[30] G. I. Cook, R. L. Marsh and J. L. Hicks, "Halo and Devil Effects Demonstrate Valence-Based Influences on SourceMonitoring Decisions," Consciousness and Cognition, Vol. 12, No. 2, 2003, pp. 257-278. doi:10.1016/S1053-8100(02)00073-9

[31] M. S. Albert and D. Blacker, "Mild Cognitive Impairment and Dementia," Annual Review of Clinical Psychology, Vol. 2, 2006, pp. 379-388. doi:10.1146/annurev.clinpsy.1.102803.144039

[32] P. W. Burgess, J. S. Simons, I. Dumontheil and S. J. Gilbert, "The Gateway Hypothesis of Rostral Prefrontal Cortex (Area 10) Function,” In: J. Duncan, P. McLeod and L. Phillps, Eds., Measuring the Mind: Speed, Control and Age, Oxford University Press, Oxford, 2005, pp. 217-248. doi:10.1093/acprof:oso/9780198566427.003.0009

[33] P. W. Burgess, S. K. Scott and C. D. Frith, “The Role of the Rostral Frontal Cortex (Area 10) in Prospective Memory: A Lateral versus Medial Dissociation,” Neuropsychologia, Vol. 41, No. 8, 2003, pp. 906-918. doi:10.1016/S0028-3932(02)00327-5

[34] J. Okuda, T. Fujii, A. Yamadori, R. Kawashima, T. Tsukiura, R. Fukatsu, et al., "Partecipation of the Prefrontal Cortices in Prospective Memory: Evidence from a PET Study in Humans,” Neuroscience Letters, Vol. 253, No. 2, 1998, pp. 127-130. doi:10.1016/S0304-3940(98)00628-4

[35] J. S. Simons, M. L. Schölvinck, S. J. Gilbert, C. D. Frith and P. W. Burgess, "Differential Components of Prospective Memory? Evidence from FMRI,” Neuropsychologia, Vol. 44, No. 8, 2006, pp. 1388-1397. doi:10.1016/j.neuropsychologia.2006.01.005

[36] J. Poppenk, M. Moscovitch, A. R. McIntosh, E. Ozcelik and F. I. Craik, "Encoding the Future: Successful Processing of Intentions Engages Predictive Brain Networks," Neuroimage, Vol. 49, No. 1, 2010, pp. 905-913. doi:10.1016/j.neuroimage.2009.08.049

[37] H. Cheng, Y. Tian, P. Hu, J. Wong and K. Wang, “TimeBased Prospective Memory Impairments in Patients with Thalamic Stroke,” Behavioral Neuroscience, Vol. 124, No. 1, 2010, pp. 152-158. doi:10.1037/a0018306

[38] S. J. Gilbert, P. M. Gollwizer, A. L. Cohen, G. Oettingen, "Separable Brain Systems Supporting Cued versus SelfInitiated Realization of Delayed Intentions,” Journal of Experimental Psychology: Learning, Memory \& Cognition, Vol. 35, No. 4, 2009, pp. 905-915. 


\section{doi:10.1037/a0015535}

[39] E. Volle, G. Goneen-Yaacovi, A. de Lacy Costello, S. J. Gilbert and P. W. Burgess, "The Role of Rostrale Prefrontal Cortex in Prospective Memory: A Voxel-Based Lesion Study,” Neuropsychologia, Vol. 49, No. 8, 2011, pp. 2189-2198.

doi:10.1016/j.neuropsychologia.2011.02.045

[40] P. W. Burgess and T. Shallice, "The Relationship between Prospective and Retrospective Memory: Neuropsychological Evidence,” In: M. M. Conway, Ed., Cognitive Models of Memory, MIT Press, Cambridge, 1997.

[41] M. A. Brandimote, G. O. Einstein and M. A. McDaniel, "Prospective Memory: Theory and Applications," Erlbaum, Hillsdale, 1996.

[42] M. Kliegel, M. J. Guynn and H. Zimmer, "The Role of Noticing in Prospective Memory Forgetting," International Journal of Psychophysiology, Vol. 64, No. 3, 2006, pp. 226-232.

[43] A. L. Cohen, R. West and F. I. Craik, "Modulation of the Prospective and Retrospective Components of Memory for Intentions in Younger and Older Adults," Aging, Neuropsychology, and Cognition, Vol. 8, No. 1, 2001, pp. 1-13. doi:10.1076/anec.8.1.1.845

[44] E. E. Smith and J. Jonides, "Storage and Executive Processes in the Frontal Lobes," Science, Vol. 283, No. 5408, 1999, pp. 1657-1661. doi:10.1126/science.283.5408.1657

[45] M. J. Guynn, "A Two-Process Model of Strategic Monitoring in Event-Based Prospective Memory: Activation/ Retrieval Mode and Checking," International Journal of Psychology, Vol. 38, No. 4, 2003, pp. 245-256. doi:10.1080/00207590344000178

[46] A. R. Doobs and B. G. Rule, "Prospective Memory and Self-Report of Memory Abilities," Canadian Journal of Psychology, Vol. 41, No. 2, 1987, pp. 209-222. doi: $10.1037 / \mathrm{h} 0084152$

[47] P. W. Burgess, A. Quayle and C. D. Frith, "Brain Regions Involved in Prospective Memory as Determined by Positron Emis-Sion Tomography," Neuropsychologia, Vol. 39, No. 6, 2001, pp. 545-555. doi:10.1016/S0028-3932(00)00149-4

[48] E. A. Maylor, "Prospective Memory in Normal Ageing and Dementia," Neurocase, Vol. 1, No. 3, 1995, pp. 285289. doi:10.1080/13554799508402372

[49] J. A. Meacham and B. Leiman, "Remembering to Perform Future Actions,” In: U. Neisser, Ed., Memory observed: Remembering in Natural Contexts, Freeman, San Francisco, 1982, pp. 327-336.

[50] M. Moscovitch, "Memory and Working with Memory: Evaluation of a Component Process model and Comparisons with Other Models” In: D. L. Shacter, and E. Tulving, Eds., Memory systems, MT Press, Cambridge, 1994, pp. 269-310.

[51] F. Collette, M. Van der Linden and E. Salmon, "Executive Dysfunction in Alzheimer's Disease," Cerebral Cortex, Vol. 35, No. 1, 1999, pp. 57-72.

[52] A. Blanco-Campal, R. F. Coen, B. A. Lawlor, J. B. Walsh and T. E. Burke, "Detection of Prospective Memory Deficits in Mild Cognitive Impairment of Suspected Alz- heimer's Disease Etiology Using a Novel Event-Based Prospective Memory Task," Journal of the International Neuropsychological Society, Vol. 15, No. 1, 2009, pp. 154-159. doi:10.1017/S1355617708090127

[53] H. Kazui, A. Matsuda, N. Hirono, E. Mori, N. Miyoshi, A. Ogino, H. Tokunaga, Y. Ikejiri and M. Takeda, "Everyday Memory Impairment of Patients with Mild Cognitive Impairment," Dementia and Geriatric Cognitive Disorders, Vol. 19, No. 5-6, 2005, pp. 331-337. doi:10.1159/000084559

[54] A. Costa, G. A. Carlesimo and C. Caltagirone, "Prospective Memory Functioning: New Area of Investigation in the Clinical Neuropsychogy and Rehabilitation of Parkinson's Disease and Mild Cognitive Impairment. Review of Evidence,” Neurological Studies, Vol. 33, No. 5, 2012, pp. 965-972.

[55] S. Karantzoulis, A. Tryer and J. B. Rich, "Prospective Memory in Amnestic Mild Cognitive Impairment,” Journal of the International Neuropsychological Society, Vol. 15, No. 3, 2009, pp. 407-415. doi:10.1017/S1355617709090596

[56] J. D. Greene, J. R. Hodges and A. D. Baddeley, “Autobiographical Memory and Executive Function in Early Dementia of Alzheimer Type," Neuropsychologia, Vol. 33, No. 12, 1995, pp. 1647-1670. doi:10.1016/0028-3932(95)00046-1

[57] A. K.Troyer and K. J. Murphy, "Memory for Intentions in Amnestic Mild Cognitive Impairment: Time- and EventBased Pro-Spective Memory," Journal of the International Neuropsychological Society, Vol. 13, No. 2, 2007, pp. 365-369. doi:10.1017/S1355617707070452

[58] R. L. Marsh, J. L. Hicks and G. I. Cooks, "On the Relationship between Effort toward an Ongoing Task and Cue Detection in Event-Based Prospective Memory. Journal of Experimental Psychology: Learning, Memory, and Cognition, Vol. 31, No. 1, 2005, pp. 68-75. doi:10.1037/0278-7393.31.1.68

[59] J. H. Kramer, A. Nelson, J. K. Johnson, K. Yaffe, S. Glenn, H. J. Rosen and B. L. Miller, "Multiple Cognitive Deficits in Amnestic Mild Cognitive Impairment," Dementia and Geriatric Cognitive Disorders, Vol. 22, No. 4, 2006, pp. 306-311. doi:10.1159/000095303

[60] G. O. Einstein and M. A. McDaniel, "Prospective Memory and What Costs Do Not Reveal about Retrieval Processes. A Com-Mentary on Smith, Hunt, Mcvay, and Mcconnell (2007),” Journal of Experimental Psychology: Learning, Memory \& Cognition, Vol. 36, No. 4, 2008, pp. 1082-1088. doi:10.1037/a0019184

[61] M. J. Guynn, “Theory of Monitoring in Prospective Memory: Instantiating Retrieval Mode and Periodic Target Checking,” In: M. Kliegel, M. A.McDaniel and G. O. Einstein, Eds., Perspective Memory: Cognitive, Neuroscience, Developmental and Applied Perspective," Lawrence Erlbaum Associates, New York, 2008, pp. 53-76.

[62] G. Cona, G. Arcara, V. Tarantino, P. A. Bisiacchi, "Electrophysiological Correlates of Strategic Monitoring in Event-Based and Time-Based Prospective Memory," PloS One, Vol. 7, No. 2, 2012, p. e31659.

[63] R. Perri, G. A. Carlesimo, L. Serra and C. Caltagirone, 
"Characterization of Memory Profile in Subjects with Mild Cognitive Impairment,” Journal of Clinical and Experimental Neuropsychology, Vol. 27, No. 8, 2005, pp. 1033-1055. doi:10.1080/13803390490919317

[64] A. S. Zigmond and R. P. Snaith, "The Hospital Anxiety and Depression Scale," Acta Psychiatrica Scandinavica, Vol. 67, No. 6, 1983, pp. 361-370. doi:10.1111/j.1600-0447.1983.tb09716.x

[65] R. C. Petersen, "Mild Cognitive Impairment as a Diagnostic Entity,” Journal of Internal Medicine, Vol. 256, No. 3, 2004, pp. 183-194. doi:10.1111/j.1365-2796.2004.01388.x

[66] A. Orsini, D. Grossi, E. Capitani, M. Laiacona, C. Papagno and G. Vallar, "Verbal and Spatial Immediate Memory Span; Normative Data from 1355 Adults and 1112 Children," Italian Journal of Neurological Sciences, Vol. 8, No. 6, 1987, pp. 539-48. doi:10.1007/BF02333660

[67] J. C. Raven, "Progressive Matrices,” Lewis, London, 1947.

[68] D. Wechsler, "Wechsler Adult Intelligence Scale-III," Psychological Corporation, New York, 1997.

[69] S. Della Sala, A. Baddeley, C. Papagno and H. Spinnler, "Dual task paradigm: A Means to Examine the Central Executive," Annals of the New York Academy of Sciences, Vol. 769, No. 1, 1995, pp. 161-172. doi:10.1111/j.1749-6632.1995.tb38137.x

[70] P. Caffarra, G. Vezzadini, F. Dieci, A. Zonato, and A. Venneri, "Una Versione Abbreviata del Test di Stroop: Dati Normativi Nella Popolazione Italiana," Nuova Rivista di Neurologia, Vol. 12, No. 4, 2002, pp. 111-115.
[71] R. Krikorian, J. Bartok and N. Gay, "Tower of London Procedure: A Standard Method and Developmental Data," Journal of Clinical and Experimental Neuropsychology, Vol. 16, No. 6, 1994, pp. 840-850. doi:10.1080/01688639408402697

[72] G. A. Carlesimo, C. Caltagirone and G. Gainotti, "The Mental Deterioration Battery: Normative Data, Diagnostic Reliability and Qualitative Analyses of Cognitive Impairment. The Group for the Standardization of the Mental Deterioration Battery," European Journal of Neurology, Vol. 36, No. 6, 1996, pp. 378-384. doi:10.1159/000117297

[73] G. Novelli, et al., "Three Clinical Tests for the Assessment of Verbal Long-Term Memory Function: Norms from 320 Normal Subjects," Archivio di Psicologia Neurologia e Psichiatria, Vol. 47, No. 2, 1986, pp. 278-296.

[74] P. Caffarra, G. Vezzadini, F. Dieci, A. Zonato, and A. Venneri, "Rey-Osterrieth Complex Figure: Normative Values in an Italian Population Sample," Neurological Science, Vol. 22, No. 6, 2002, pp. 443-447.

[75] G. O. Einstein and M. A. McDaniel, "Strategic and Automatic Processes in Prospective Memory Retrieval: A Multi-Process Framework," Applied Cognitive Psychology, Vol. 14, No. 7, 2000, pp. 127-144. doi:10.1002/acp.775

[76] H. Spinnler and G. Tognoni, "Standardizzazione e Taratura Italiana di Test Neuropsicologici,” The Italian Journal of Neurological Sciences, Vol. S8, No. 6, 1987, pp. 44-46. 